\title{
Correction to: Intimate Partner Violence and Coerced Unprotected Sex Among Young Women Attending Community College
}

\author{
Lindsay M. Orchowski ${ }^{1}$ (1) $\cdot$ Miryam Yusufov ${ }^{2,3} \cdot$ Daniel Oesterle $^{2,4} \cdot$ Katherine W. Bogen $^{2} \cdot$ Caron Zlotnick ${ }^{5,6,7}$
}

Published online: 2 January 2020

○) Springer Science+Business Media, LLC, part of Springer Nature 2020

Correction to: Archives of Sexual Behavior https://doi.org/10.1007/s10508-019-01537-5

There is an error in one of the affiliations presented for coauthor Caron Zlotnick:

The city and country for the University of Cape Town should be Cape Town, South Africa, rather than Providence, RI, USA.

Publisher's Note Springer Nature remains neutral with regard to jurisdictional claims in published maps and institutional affiliations.

The original article can be found online at https://doi.org/10.1007/ s10508-019-01537-5.

Lindsay M. Orchowski

Lindsay_Orchowski@Brown.edu

1 Department of Psychiatry and Human Behavior, Rhode Island Hospital, Warren Alpert Medical School of Brown University, 146 West River Street, Suite 11B, Providence, RI 02904, USA

2 Department of Psychiatry, Rhode Island Hospital, Providence, RI, USA

3 Department of Psychiatry, McLean Hospital, Harvard Medical School, Belmont, MA, USA

4 Department of Health Policy and Behavioral Sciences, Mark Chaffin Center for Healthy Development, School of Public Health, Georgia State University, Atlanta, GA, USA

5 Department of Behavioral Medicine, Women and Infants Hospital, Providence, RI, USA

6 Department of Psychiatry and Human Behavior, Warren Alpert Medical School of Brown University, Providence, RI, USA

7 Department of Psychiatry and Mental Health, University of Cape Town, Cape Town, South Africa 